OPDIMUM: Jurnal Ekonomi dan Pembangunan
VOL 11, No. 2, 232-242
$\begin{aligned} & \text { Universitas } \\ & \text { Ahmad Dahlan }\end{aligned}$
https://dx.doi.org/10.12928/optimum.v11i2.4653

\title{
Consumer Acceptance and Willingness to Pay for Prebiotic Kuini Juice in Malaysia
}

\author{
Norzalila Kasron",a; Siti ‘Aisyah Baharudin'2,b*; Saiful Bahri Saari ${ }^{3, c}$, Mohd Nur \\ Hafiz Mat Azmin 4,d; Nor Azlina Saari 5,e \\ 1ํㅡorzalila@mardi.gov.my; ${ }^{2}$ sab16@usm.my; ${ }^{3}$ saiful@mardi.gov.my; ${ }^{4}$ mnh@mardi.gov.my; \\ 5inasaari@mardi.gov.my
}

a, c, d, eMalaysia Agricultural Research Development Institute; bUniversiti Sains Malaysia

*corresponding authors

ARTICLE INFO

Article history

Received : 10-08-2021

Revised : 18-09-2021

Accepted : 23-09-2021

Keywords

Consumer Acceptance

Kuini

MARDI

Prebiotic drink

Willingness to Pay

\section{AB STR ACT}

Changing consumers' lifestyles and food consumption patterns provide an excellent opportunity to develop the prebiotics market in Malaysia. Therefore, Malaysia is trying to improve products based on local ingredients such as kuini juice developed by the Malaysian Agricultural Research and Development Institute (MARDI). The high fibre content found in kuini makes it suitable to be used as one of the essential ingredients in prebiotic drinks. This research attempted to analyse consumer acceptance and willingness to pay for prebiotic kuini juice. A survey was conducted in Peninsular Malaysia, where 400 respondents were interviewed using a structured questionnaire. Exploratory factor analysis, Kaiser-Meyer-Olkin test and Bartlett's Test of Sphericity were utilised for objective analysis 1, while the Contingent Valuation Method was utilised for objective analysis 2 . The result showed that $73 \%$ of respondents had taken prebiotic juice in the past. The tendency to choose prebiotic kuini juice by MARDI was $52 \%$ compared to existing products in the market. Significant findings determined consumers' preference factors, including product marketing and promotion, which influenced the purchasing of prebiotic kuini juice. The willingness to pay by respondents was lower at RM4.10/300ml bottle than the actual price bid at RM5.70/300ml bottle. As consumer awareness of health increases, it was an opportunity for the health food industry to expand the functional food market. However, some improvements should be adjusted to ensure prebiotic kuini juice can compete with other similar products in the market. Government support is needed to encourage indigenous fruits cultivation and to produce value-added products.

This is an open-access article under the CC-BY-SA license.

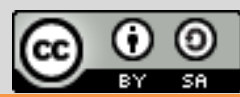

\section{Introduction}

Nowadays, consumers are interested in buying healthy products, influenced by lifestyle, social media, and awareness of healthy food consumption. Prebiotics is one of the health products that are increasingly gaining attention globally. It is defined as undigested food ingredients beneficial to the 'host' to promote the growth or activity of certain bacteria in the colon (Gibson \& Roberfroid, 1995). The global prebiotics market demand was 623.5 kilotons in 2015, while the value was USD 3.4 billion in 2018 and is forcasted to reach USD 
8.34 Billion by 2026. The Compound Annual Growth Rate (CAGR) of market demand growing at $8.0 \%$ from 2016 to 2024. European market dominated the global prebiotics industry and is expected to witness a CAGR of 10.2\% from 2016 to 2024, followed by North America with a CAGR of $9.7 \%$ for the same period. The Asia Pacific market anticipated witnessing a CAGR at $10.7 \%$ from 2016 to 2024, demand-driven by high population countries such as China, and India. In addition, the prebiotics market in Australia is driven by a search for food-based drug substitutes and combat-related lifestyle diseases (GlobeNewswire, 2020).

The prebiotic industry in Asia is gaining momentum (Scott et al., 2020), including Malaysia. Changes in consumer taste towards a balanced diet in Malaysia impact the increasing demand for prebiotic products. There was a various initiative in line with the increase in prebiotic consumption such as the production of prebiotic beverages by The Malaysian Agricultural Research and Development Institute (MARDI). MARDI is in the process of launching a new beverage product, the prebiotic kuini juice. Kuini or its scientific name Mangifera Odorata is one of the indigenous fruits in Malaysia. Among the features of kuini juice products that MARDI will release are the followings: i) supports a soluble a highfibre diet that conforms to the feature of prebiotic products; ii) following the low glycemic index (GI), which is suitable for diabetes; and iii) ready to drink product

The daily fibre intake in Malaysia is still low. The Malaysian Dietetic Association recommends a dietary fibre intake of $25 \mathrm{~g}$ per day, and out of this number, $7 \mathrm{~g}$ to $13.5 \mathrm{~g}$ is necessary from a soluble fibre source such as grains, nuts, fruits and vegetables (Markowiak \& Śliżewska, 2017). The prebiotic kuini juice is high in fibre $(3.5 \mathrm{~g} / 100 \mathrm{ml})$. The daily intake of juice by $300 \mathrm{ml}$ provides 10.5 grams of soluble dietary fibre, which exceeds the minimum recommendation of daily dissolved dietary fibre. The positive effect of prebiotic on health is associated with a decrease in the incidence of some diseases, including cardiovascular disease, by stabilising cholesterol, blood sugar, body fat content. Plus, it is a good food source for the good bacteria in the gut (Zhou et al., 2015: Slavin, 2013). The high demand and attention driven by ready-to-drink products are due to various factors, including being consumed directly and the ease of carrying and modification by size and shape according to customer preferences.

Therefore, research related to consumer acceptance and willingness to pay is essential before new products are launched, especially in the healthy drinks category. The study aims to identify consumer acceptance and willingness to pay for prebiotic kuini juice developed by MARDI. 


\section{Consumer Acceptance}

Market pre-validation is an evaluation activity in the industry to gather feedback and improve the product based on suitability and industry needs to ensure the products are ready for the commercial phase (Olsen, 2015). This process is vital to reduce the risk of product failure in the commercialisation phase. The failure happened when the gut feeling was used in the research area. It was a situation where the technologies developed based on technology push and not by demandpull. According to Andreessen (2019), the product-market fit needs to ensure that the products meet consumers' demands. Therefore, the Product-Market Fit Pyramid is applied, which contents of six steps hierarchical for completing product-market validation and achieving product-market fit as presented in Figure 1 below. There are two layers of Product-Market Fit Pyramid, namely market and product. Market elements target consumers and underserved needs. While products elements include value proposition, feature set and user experience.

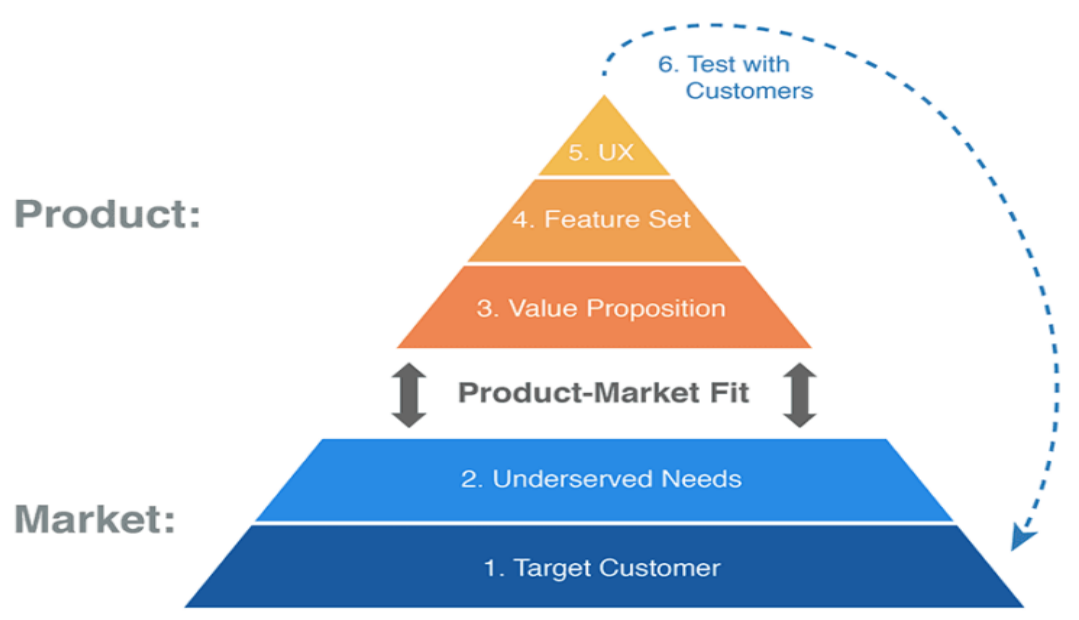

Source: The Lean Product Playbook (Olsen, 2015)

Figure 1. Product-Market Fit Pyramid

Lim \& Goh (2019) examined attitudes, subjective norms, perceived behavioural control, brand, awareness, and belief, influencing the intention to buy healthy drinks among urban consumers in Malaysia. The results supported the standard Theory of Planned Behaviour model's attitudes, subjective norms, and behavioural control. Belief as an additional determinant has also been shown to influence consumers' purchasing intentions towards healthy beverages. Beliefs and awareness also have a positive and significant relationship with consumers' attitudes toward healthy drinks. Surprisingly, brand and awareness were insignificant in influencing consumers' purchasing intentions toward healthy beverages.

\section{Willingness to Pay}

Knowledge of the willingness to pay for products on behalf of potential consumers plays a vital role in many areas of marketing management, such as pricing decisions or new product development. Willingness to pay is the amount of money that represents the 
difference between consumer surplus before and after adding or improving food product attributes (Rodríguez et al., 2007). Several studies on willingness to pay for healthy food products have been conducted across the globe. Analysis of the study by Ali \& Ali (2020) showed that $44 \%$ of consumers were willing to pay an average of $9 \%$ additional price to purchase the health and wellness food products they desire. The demographic variables (income and education) were more likely to influence consumers' willingness to pay for healthy food products. Health awareness was a major psychological factor for buyers that influenced their willingness to purchase, followed by product quality, taste, finish, and price. Consumers found convenience in shopping and were less influenced by market supply or in-store sales assistance. Another study conducted by (Talati et al., 2017) showed that consumers were willing to pay a higher price if the front pack label of health food products is displayed compared to the pack label without health information.

\section{Method}

Data analysis was conducted on 400 respondents using a structured questionnaire and face-to-face interviews. The sampling size focuses on the population in Peninsular Malaysia and is selected by stratified random sampling technique to ensure the subgroup represented the $\mathrm{N}$ population. The sample size is divided into four states in Malaysia, North $(n=100)$, South $(n=100)$, West $(n=100)$ and East $(n=100)$ and the major survey locations included malls and hypermarkets. These are the number of individuals out of the population who will participate and achieve the required sampling size based on the expected response rate. The sample size is adequate for statistical analysis to be conducted, and more conclusive inferences can be made from the findings. The number is also appropriate, considering the time and resource constraints of this research.

\section{To identify consumer acceptance of prebiotic kuini juice}

The Product-Market Fit Pyramid is utilised to ensure the products meet consumers' demands. Interviews, focus group discussions, and surveys were part of product testing to measure consumers' preferences. Food testing is conducted for two juice samples, including prebiotic kuini juice and product from the market with sensory characteristics equivalent to prebiotic kuini juice. Respondents must taste the samples provided to evaluate the attributes such as colour, sweetness, sourness, fruit flavour, aroma, viscosity, fibre, and after taste. Respondents answered the question by marking the preferred answer based on the Likert Scale as 1 = Strongly Dislike, 2 = Dislike, $3=$ Not Sure, $4=$ Like, and $5=$ Very Like.

Exploratory Factor Analysis (EFA), Kaiser-Meyer-Olkin (KMO) test, and Bartlett's Test of Sphericity are utilised to analyse consumer acceptance of prebiotic kuini juice. EFA is 
used to discover the underlying structure of observed variables (Mvududu \& Sink, 2013). The items are reduced to a small set of underlying factors that summarise the essential information contained in the variables. KMO test and Bartlett's Test of Sphericity were conducted to verify whether the data set was suitable for factor analysis. The tests measure the sampling adequacy to determine the factorability of the matrix or data set as a whole (Richard \& Dean, 2007). The data set of factorability can be assumed to exist when the value of Bartlett's Test of Sphericity is large and significant while the KMO value is greater than 0.50. Factor loading is the correlation coefficient for the variable, and it explains the variance by the variable on that particular factor. The value must exceed 0.3 , while eigenvalues must exceed ' 1 ' to be classified as one factor. The communality value for each item must be within the 0.3 range to confirm whether all factors extracted from this analysis are reliable or not, as suggested by MacCallum et al. (1999).

\section{To identify willingness to pay for prebiotic kuini juice}

The regression model to determine the actual value of the Willingness to Pay (WTP) is based on A. Krystallis \& Chryssohoidis (2005) that can be stated as follows:

$$
W T P=\frac{\left[\beta_{0}+\left(\beta_{2} X_{2}+\beta_{3} X_{3}+\ldots, \beta_{k} X_{k}\right)\right]}{\beta_{1}}
$$

When $B_{0}, B_{2}, B_{3}, B_{K}$ and $B_{1}$ represent the coefficient values for constant, bid price, producer, income, education and age, respectively. The respondent's vote cannot influence such provision; truth-telling is in the respondent's best interest (Hoehn \& Randall, 1987). This method can estimate the probability of answering YES for the independent variablerate bid, and some assumptions made regarding the upper limit values and lower limits for each bid rate are integral. The probability of saying 'YES' is one (1), while the probability of saying 'NO' is zero (0). As a result, the negative value of WTP can be deducted, and zero is used as a lower limit value.

The study utilised the Contingent Valuation Method to estimate the population's value on a good. The approach asked their WTP to obtain a specified good or Willingness to Accept (WTA) to give up a good, rather than infer from observed behaviours in regular marketplaces. The dichotomous choice approach mimics behaviour in traditional markets where people usually purchase or decline the purchase, which is good at the posted prices. The method has also been shown to be incentive-compatible, proved that respondents understood the excellent provision depends on most votes.

\section{Result and Discussion}

A total of 400 surveys were completely conducted. Table 1 presents the background characteristics of respondents. The study found that $68 \%$ of the respondents involved in 
this study were above 40 years old. In addition, $59 \%$ of respondents had higher education, while the rest had a secondary school level or below education. Respondents working in the private sector were $35 \%, 32 \%$ in the government sector, $12 \%$ were self-employed, and the rest were retirees, housewives or students. The Malaysian household income group consist of three income groups range, namely B40, M40 and T20.72\% of respondents fall in the B40 with an income less than RM4,850. 22\% of respondents fall in the M40 group with an income range of more than RM5000 and less than RM10,970. The rest are respondents from the T20 group, with an income range exceeding RM10,971 (DOSM, 2020).

\section{Table 1: Demographic profile of consumer survey $(n=400)$}

\begin{tabular}{llc}
\hline Characteristic & & \% \\
\hline \multirow{4}{*}{ Age } & $<=20$ & 7 \\
& $21-30$ & 30 \\
Education Level & $31-40$ & 31 \\
& $41-50$ & 22 \\
& $51-60$ & 7 \\
& $>60$ & 3 \\
& No formal education & 1 \\
Job & Primary school & 2 \\
& Secondary school & 38 \\
& Higher education & 59 \\
& Government & 32 \\
& Private & 35 \\
& Self-employed & 12 \\
& Retiree & 4 \\
Household Income & Housewife & 6 \\
& Student & 11 \\
& $<$ RM2,500 & 41 \\
& RM2,501 - RM4,850 & 31 \\
& RM4,851 - RM7,100 & 13 \\
& RM7,101 - RM10,970 & 9 \\
& RM10,971 - 15,040 & 5 \\
& $>$ RM15,041 & 1
\end{tabular}

\section{Consumer Acceptance towards Prebiotic Kuini Juice}

The survey was conducted on two products, including prebiotic kuini juice drinks developed by MARDI and a randomly selected juice from the market with similar attributes to identify consumers' acceptance. The potential for functional foods is promising, as consumer generally wants to buy healthy food (Brunsø et al., 1996). Still, at the same time, consumers are reluctant to change their unhealthy eating habits (Williamson et al., 2000). These statements align with this study results; a field survey showed that $54 \%$ of 
respondents knew of functional foods, proving awareness of functional foods among Malaysians. However, $47 \%$ had consumed the products.

Table 2: Statistical Descriptive Analysis of Prebiotic Juice

\begin{tabular}{lcccc}
\hline \multirow{2}{*}{ Attribute } & \multicolumn{2}{c}{ Prebiotic Kuini Juice } & \multicolumn{2}{c}{ Existing Product } \\
\cline { 2 - 4 } & Mean & Sd. Deviation & Mean & Sd. Deviation \\
\hline Colour & 3.98 & 0.895 & 4.14 & 0.786 \\
Sweetness & 3.91 & 0.950 & 3.97 & 0.902 \\
Sourness & 3.78 & 0.962 & 3.93 & 0.954 \\
Fruit Flavour & 4.21 & 0.831 & 4.08 & 0.918 \\
Aroma & 3.90 & 0.999 & 3.85 & 0.993 \\
Viscosity & 3.89 & 1.089 & 3.87 & 0.982 \\
Fibre & 4.02 & 0.906 & 3.84 & 0.948 \\
After Taste & 3.97 & 0.972 & 4.04 & 0.939 \\
\hline
\end{tabular}

Note: 1 = Strongly Dislike, 2 = Dislike, $3=$ Neutral, 4 = Like and 5 = Very Like

The survey indicated that $73 \%$ of respondents had consumed prebiotic juice, while the rest had never drunk it. Consumers preferred the features of MARDI products such as fruit flavour, aroma, viscosity and fibre compared to existing products in the market, as shown in Table 2. The tendency to choose between these two products also showed that $52 \%$ of respondents chose prebiotic kuini juice compared to existing products in the market.

Table 3: Factor influencing the purchase of Prebiotic Kuini Juice

\begin{tabular}{lcc}
\hline \multirow{2}{*}{ Items } & \multicolumn{1}{c}{ Factor } & \\
\cline { 2 - 3 } & Product and Marketing & Promotion \\
\hline Price & & 0.786 \\
Discount & & 0.819 \\
Brand & & 0.570 \\
Packaging size (300 ml, 1,000 ml) & 0.504 \\
Labelling & & \\
Type of packaging (glass bottle, plastic bottle, box) & 0.616 \\
Nutritional value & 0.547 & \\
Producer (local, imported) & 0.611 & \\
Advertisement channel (Social, electronic, printed media) & 0.669 \\
Advertisement time & 0.727 & 1.300 \\
Eye's level & 0.613 & 10.000 \\
Easy to access & 0.680 & 49.995 \\
Marketing channel (online, conventional, conventional) & \\
Eigenvalue & 0.659 & \\
Variance (\%) & 0.703 & \\
Cumulative of variance (\%) & 5.199 \\
Kaiser-Meyer-Olkin & 39.995 \\
Bartlett's Test of Sphericity & 39.995 \\
\hline
\end{tabular}


Out of the 14 variables analysed in Table 3, the Kaiser-Meyer-Olkin test provided a value of 0.881, while the Barlett's test result was significant at 0.01 ( $p$-value $=0.000)$. These values showed that factor analysis could identify the main factors that influence prebiotic kuini juice purchase. Eigenvalues exceeding 1.0 are considered factors that influence the purchase. The analysis has reduced the number of original variables to new factors. Thirteen items were extracted into two factors; both described as $50 \%$ variance in the study - these factors were categorised as Product and Marketing and promotion. Hence, it can be concluded that even though consumers knew about functional foods, it was not a determinant factor for consumers to shift to a healthy daily lifestyle.

The first factor labelled as Product and Marketing explains $40 \%$ of the total variance. Nine variables represent this factor, and two of them provided a high correlation value $>$ $0.7)$, namely the marketing method (0.703) and advertising channel (0.727). The results indicated that $60 \%$ of respondents agreed to make sales available online due to the ease of access. $67 \%$ of respondents also agreed that advertising channels had targeted them through social media. The second factor is labelled as promotion which explains $9.80 \%$ of the total variance. Four variables represent this factor, and three provided a high correlation value of more than 0.7 . The variable with a very high correlation value $(>0.8)$ is the discount given to the buyer (0.819), while the high correlation value $(>0.7)$ is the price offered (0.786). Consumer acceptance of this study differs from several previous studies that showed knowledge of the benefits of prebiotic products and awareness of healthy foods play an essential role in consumer purchasing (Arora, 2020; Yilmaz-Ersan et al., 2020). These differences may be due to variations in the types of prebiotic products studied.

\section{Willingness to pay for Prebiotic Kuini Juice}

In general, willingness to pay is the maximum amount a consumer can pay to acquire goods or services. Table 4 shows the actual price bid is RM5.70/ bottle $(300 \mathrm{ml})$; however, after analysing the WTP formula, respondents' price willing to be paid is only RM4.10/bottle $(300 \mathrm{ml})$. Moreover, local producers are more significant than international producers in the selection of prebiotic beverage products. Income significantly influences their WTP while age is not significant. The findings are consistent with the economic theory, which shows that demand will decline when prices rise, and WTP will decline as the prices asked of respondents' increase (Hanley \& Barbier 2009). It also means that the higher the bid value offered increases the responses' resistance to paying for prebiotic kuini juice developed by MARDI. 
Table 4: Consumers' Willingness to Pay, $n=400$

\begin{tabular}{lcccccc}
\hline & $\boldsymbol{B}$ & $\boldsymbol{S . E}$ & Wald & $\boldsymbol{d f}$ & $\boldsymbol{S} \boldsymbol{\text { Sig. }}$ & $\boldsymbol{E x p ( B )}$ \\
\hline Bid Price & -0.203 & 0.070 & 8.478 & 1 & 0.004 & 0.817 \\
Producer & 0.877 & 0.310 & 8.024 & 1 & 0.005 & 2.405 \\
Income & -1.303 & 0.770 & 2.864 & 1 & 0.091 & 0.272 \\
Education & -0.408 & 0.240 & 2.880 & 1 & 0.090 & 0.665 \\
Age & 0.278 & 0.258 & 1.162 & 1 & 0.281 & 1.320 \\
Constant & 0.129 & 0.417 & 0.095 & 1 & 0.758 & 1.137 \\
\hline -2 Log likelihoods & & \multicolumn{7}{c}{459.381} \\
Cox and Snell R Square & & 0.062 & & \\
Nagelkerke R Square & & 0.088 & & \\
\hline
\end{tabular}

Conclusion

This study identifies the acceptance of consumers and willingness to pay towards the products developed by MARDI based on selected indigenous fruits. Food testing conducted on prebiotic kuini juice and an equivalent product selected from the market showed consumers are fond of the characteristics of MARDI product in terms of fruit taste, aroma, viscosity and fibre. The response on willingness to pay indicated that consumers would pay lower than the price that has been set. As consumer awareness of health increases, it was an opportunity for the health food industry to expand the functional food market. However, raw materials present a significant challenge in the production of the product. Furthermore, government support is needed to encourage the cultivation of indigenous fruits in Malaysia by providing seed subsidies and financial resources to farmers to expand and increase the supply of these raw materials to produce value-added products. Agencies/private companies' involvement as industrial driven is needed to create intensive/commercial plantations to commercialise downstream products based on indigenous fruits. Moreover, collaboration between research institutions and companies is crucial to catalyse the development of this industry through consumer awareness campaigns and by the creation of a market segment. Feedback on commercial prospects provided by the company/ industry is vital to ensure that the products meet consumers' needs from an industry perspective. The study is essential in helping future researchers in determining functional food production. The selection of raw materials that contain high nutrients can attract consumers to use healthy food products. The intervention of the authorities is vital in increasing the awareness of consumers in Malaysia about the benefits of functional food intake.

\section{REFERENCES}

Ali, T., \& Ali, J. (2020). Factors affecting the consumers' willingness to pay for health and wellness food products. Journal of Agriculture and Food Research, 2(100076). Retrieved from https://doi.org/10.1016/j.jafr.2020.100076. 
Andreessen, M. A Step-by-Step Guide to Product-Market Validation. Retrieved from https://www.singlemindconsulting.com/blog/a-step-by-step-guide-to-productmarket-validation/ (accessed 1 March 2021).

Arora, S., Prabha, K., Sharanagat, V. S., \& Mishra, V. (2020). Consumer awareness and willingness to purchase probiotic food and beverage products: a study of Sonipat district, Haryana. British Food Journal. Retrieved from emerald insight: https://www.emerald.com/insight/content/doi/10.1108/BFJ-06-20200469/full/html?casa_token=zS3TE56w820AAAAA:-.

Brunsø, K., Grunert, K. G., \& Bredahl, L. (1996). An analysis of national and cross-national consumer segments using the food-related lifestyle instrument in Denmark, France, Germany and Great Britain. Institut for Markedsøkonomi/MAPP Centret, Handelshøjskolen i Århus.

Olsen, D. (2015). The lean product playbook: How to innovate with minimum viable products and rapid customer feedback. John Wiley \& Sons.

Department of Statistics Malaysia (DOSM), 2020. Household Income \& Basic Amenities Survey $\quad 2020 . \quad$ Report 2 Retrieved fromhttps://www.dosm.gov.my/v1/index.php?r=column/pdfPrev\&id=TU00TmRh Q1N5TUxHVWN0T2VjbXJYZz09 (accessed 30 October 2020).

Gibson, G. R., \& Roberfroid, M. B. (1995). Dietary modulation of the human colonic microbiota: introducing the concept of prebiotics. The Journal of nutrition, 125(6), 1401-1412.

GlobeNewswire. (2020). Global Prebiotics Industry. Retrieved from https://www.globenewswire.com/fr/newsrelease/2020/10/28/2116036/0/en/Global-Prebiotics-Industry.html (accessed 28 October 2020).

Hanley, N., Barbier, E. B., \& Barbier, E. (2009). Pricing nature: cost-benefit analysis and environmental policy. Edward Elgar Publishing.

Hoehn J, Randall A. (1987). A satisfactory benefit cost indicator from contingent valuation. Journal of Environmental Economics and Management. 14(3):226-247.

Krystallis, A. and G. Chryssohoidis. (2005). Consumers' willingness to pay for organic food: Factors that affect it and variation per organic product type. British Food Journal. 107(5): 320- 343.

Lim, C. C., \& Goh, Y. N. (2019). Investigating the purchase intention toward healthy drinks among Urban consumers in Malaysia. Journal of Foodservice Business Research, 22(3), 286-302.

MacCallum, R. C., Widaman, K.F., Zhang, S., and Hong, S. (1999). Sample size in factor analysis. Psychological Methods. 4(1): 84-99.

Markowiak, P., and Śliżewska, K. (2017). Effects of probiotics, prebiotics, and Symbiotic on human health. Nutrients. 9:1021. Retrieved from https://doi.org/10.3390/nu9091021.

Mvududu, N. H., \& Sink, C. (2013). Factor analysis in counseling research and practice. Counselling Outcome Research and Evaluation. 4(2): 75-98

Richard, A. J., \& Wichern, D. W. (2007). Applied Multivariate Statistical Analysis (Sixth Edition ed.). New Jersey: Pearson Education Publications.

Rodríguez, E., Lacaze, V., \& Lupín, B. (2007). Willingness to pay for organic food in Argentina: Evidence from a consumer survey. International marketing and trade of quality food products Seminar, Italy: 187-213. 
Scott, K. P., Grimaldi, R., Cunningham, M., Sarbini, S. R., Wijeyesekera, A., Tang, M. L., ... \& Gibson, G. R. (2020). Developments in understanding and applying prebiotics in research and practice-an ISAPP conference paper. Journal of applied microbiology, 128(4), 934-949.

Slavin, J. (2013). Fiber and prebiotics: mechanisms and health benefits. Nutrients. 5 (4):1417-1435.

Talati, Z., Norman, R., Pettigrew, S., Neal, B., Kelly, B., Dixon, H., ... \& Shilton, T. (2017). The impact of interpretive and reductive front-of-pack labels on food choice and willingness to pay. International Journal of Behavioral Nutrition and Physical Activity, 14(1): 1-10.

Williamson, A. R., Hunt, A. E., Pope, J. F., and Tolman, N. M. (2000). Recommendations of dietitians for overcoming barriers to dietary adherence in individuals with diabetes. The Diabetes Educator. 26: 272-278. Retrieved from https://doi.org/10.1177/014572170002600207.

Yilmaz-Ersan, L., Ozcan, T., \& Akpinar-Bayizit, A. (2020). Assessment of socio-demographic factors, health status and the knowledge on probiotic dairy products. Food Science and Human Wellness, 9(3), 272-279.

Zhang, Y. J., Li, S., Gan, R. Y., Zhou, T., Xu, D. P., \& Li, H. B. (2015). Impacts of gut bacteria on human health and diseases. International journal of molecular sciences, 16(4), 74937519. 